\section{Conservation \\ Rainforest fragmentation kills big trees}

$\mathrm{n}$ tropical forests, large canopy and emergent trees are crucial sources of fruits, flowers and shelter for animal populations $^{1,2}$. They are also reproductively dominant ${ }^{2}$ and strongly influence forest structure, composition, gap dynamics, hydrology ${ }^{2}$ and carbon storage ${ }^{3}$. Here we show that forest fragmentation in central Amazonia is having a disproportionately severe effect on large trees, the loss of which will have major impacts on the rainforest ecosystem.

Our study area is a $1,000-\mathrm{km}^{2}$, experimentally fragmented landscape near Manaus, Brazil. More than 64,000 trees of about 1,300 species (with stem diameters larger than $10 \mathrm{~cm}$, measured at $1.3 \mathrm{~m}$ height or above any buttresses) were studied in 31 permanent 1-hectare plots in continuous forest, and 38 plots in nine forest fragments ranging from 1 to 100 ha in area.

Starting before fragment isolation in the 1980s, we checked each plot five to eight times over periods of up to 20 years (mean, 14.7 years), during which counts and diameter measurements were recorded for all living and dead trees ${ }^{4,5}$.

Before fragmentation, there was no significant difference between fragmented and continuous plots in the density of total trees or large (over $60 \mathrm{~cm}$ in diameter) trees ( $P>0.17$, Mann-Whitney $U$-tests). Large trees comprised only $1.8 \%$ of all trees, but nearly a quarter $(23.4 \%)$ of estimated above-ground forest biomass (W.F.L., unpublished data).

Plots were divided into edge (plot centre less than $300 \mathrm{~m}$ from the nearest forest edge) and interior (further than $300 \mathrm{~m}$ from the edge) categories, because it has

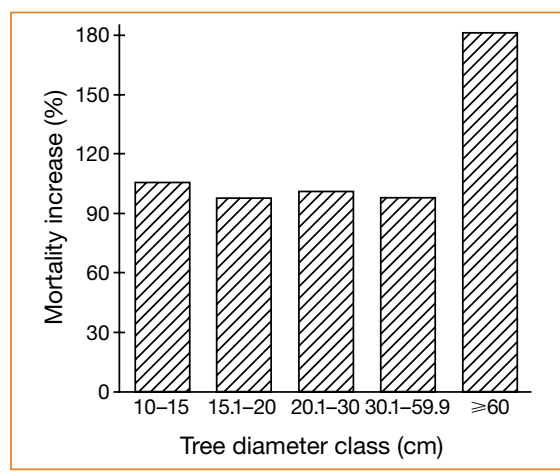

Figure 1 Percentage increase in mortality rates of rainforest trees near fragment edges, relative to rates in forest interiors. Calculated as: [(mean mortality rate on edges - mean mortality rate in interiors) $/$ mean mortality rate in interiors] $\times 100$. Sample sizes of dead trees are as follows. 10-15 cm diameter: 2,740 (edge); 1,501 (interior). 15.1-20 cm diameter: 1,308 (edge); 745 (interior). 20.1-30 cm diameter: 1,219 (edge); 684 (interior). 30.1-59.9 cm diameter: 944 (edge); 538 (interior). $>60 \mathrm{~cm}$ diameter: 137 (edge); 55 (interior)

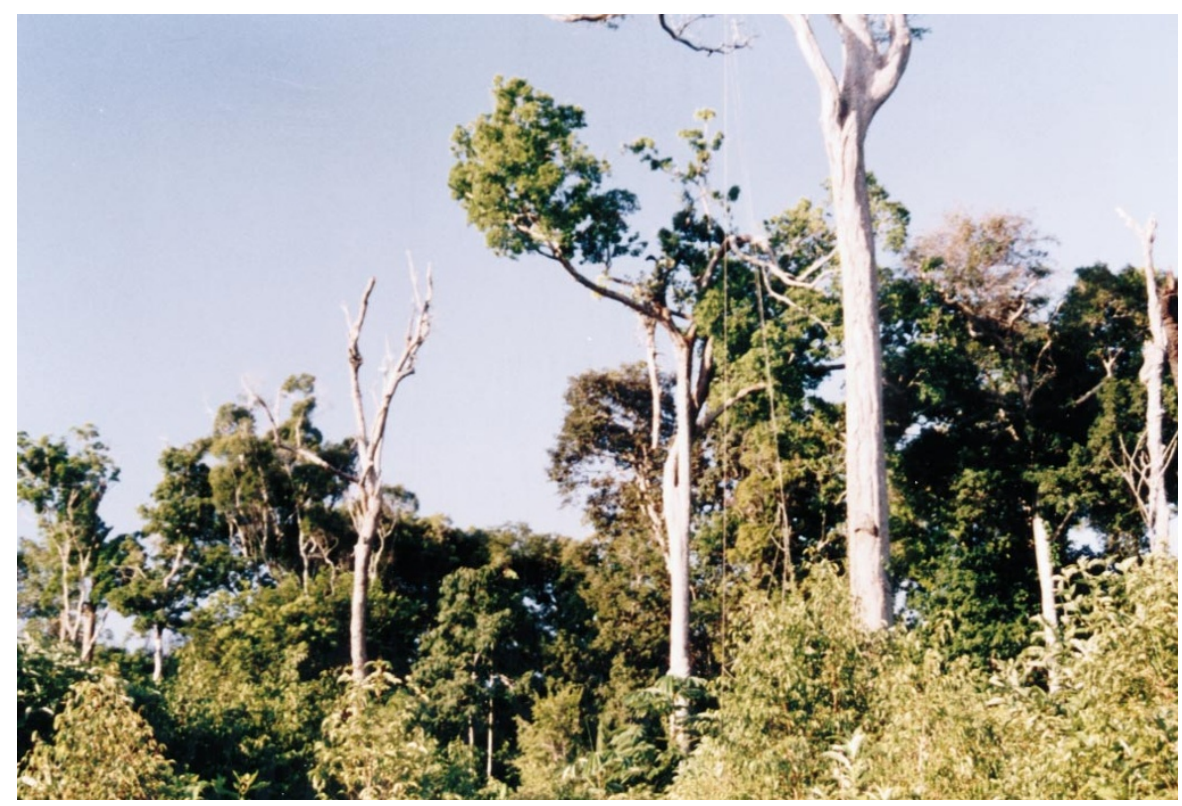

Figure 2 The fragmentation of the Amazon rainforest is having a disproportionately severe effect on large trees, which are more vulnerable to uprooting, infestation by parasitic woody vines and desiccation near forest edges.

been shown that increased tree mortality is detectable at up to $300 \mathrm{~m}$ from forest edges $^{4}$. A total of 6,348 trees died in the edge plots, whereas 3,523 died in the interior plots; annualized rates of mortality (calculated using a logarithmic model ${ }^{4}$ ) were about twice as high near edges $\left(2.49 \pm 1.50 \% \mathrm{yr}^{-1}\right)$ as they were in interiors $\left(1.23 \pm 0.43 \% \mathrm{yr}^{-1}\right)$.

Not only did many more trees die near forest edges, but a higher proportion of the dying trees were large. When the size-distributions of dead trees were compared between edge and interior plots, there were nearly equal proportions of small and medium-sized trees (under $60 \mathrm{~cm}$ diameter). For large trees, however, there was an almost $40 \%$ increase in mortality over that expected near edges - a significant difference ( $P=0.036$, d.f. $=1, G=4.38$; $G$-test $)$. The net result is that large trees died at a rate nearly three times faster $(281 \%)$ when they were within $300 \mathrm{~m}$ of edges than they did in forest interiors (Fig. 1). Furthermore, these findings may be conservative because several of our fragments are now surrounded by regrowth forest and all are protected from logging and major wildfires, factors that limit tree mortality ${ }^{6,7}$

There are at least three reasons why large trees are unusually vulnerable in fragmented rainforests. First, because of their tall stature and relatively thick, inflexible trunks, large trees may be especially prone to uprooting and breakage near forest edges, where wind turbulence is increased ${ }^{4}$. Second, lianas (woody vines) - important structural parasites that reduce tree survival $^{8}$ - increase markedly near edges and large, old trees are particularly susceptible to liana infestation ${ }^{8}$. Third, because their crowns are exposed to intense sunlight and evaporation, large tropical trees are sensitive to droughts ${ }^{1,10}$ and so may be vulnerable to increased desiccation ${ }^{11}$ near edges.

In fragmented rainforests of the Amazon (Fig. 2), the rapid rate of mortality of large trees may markedly reduce the fecundity of canopy and emergent species ${ }^{2}$, diminish forest volume and structural complexity, promote the proliferation of short-lived pioneer species ${ }^{4}$, and alter biogeochemical cycles affecting evapotranspiration ${ }^{2}$, carbon cycling $^{3}$ and greenhouse-gas emissions ${ }^{5}$. Equally alarming is the possibility that, because tree mortality is chronically increased in forest fragments ${ }^{4}$ and large trees range in age from a century to well over 1,000 years old ${ }^{3,10,12}$, their populations in fragmented landscapes may never recover. William F. Laurance ${ }^{\star} \dagger$, Patricia

Delamônica ${ }^{\star}$, Susan G. Laurance ${ }^{\star}$, Heraldo L. Vasconcelos ${ }^{\star}$, Thomas E. Lovejoy ${ }^{\star} \dagger$

${ }^{\star}$ Biological Dynamics of Forest Fragments Project, National Institute for Amazonian Research (INPA), CP 478, Manaus, Amazonas 69011-970, Brazil

$\dagger$ Smithsonian Institution, Washington DC 20560, USA

email:wfl@inpa.gov.br

Leighton, M. \& Wirawan, N. in Tropical Rain Forests and the World Atmosphere (ed. Prance, G.) 75-102 (AAAS Symposium 10, Boulder, 1986).

2. Richards, P. W. The Tropical Rain Forest (Cambridge Univ. Press, 1998).

3. Clark, D. B. \& Clark, D. A. Forest Ecol. Manage. 80, 235-244 (1995).

4. Laurance, W. F. et al. Ecology 79, 2032-2040 (1998).

5. Laurance, W. F. et al. Science 278, 1117-1118 (1997).

6. Mesquita, R., Delamônica, P. \& Laurance, W. F. Biol. Conserv. 91, 129-134 (1999).

Nepstad, D. C. et al. Nature 398, 505-508 (1999).

8. Putz, F. E. Ecology 65, 1713-1724 (1984)

9. Laurance, W. F. et al. Science 282, 1611a (1998).

10. Condit, R., Hubbell, S. P. \& Foster, R. B. Ecol. Monogr. 65, 419-439 (1995)

11. Kapos, V. J. Trop. Ecol. 5, 173-185 (1989).

12. Chambers, J. Q. et al. Nature 391, 135-136 (1998). 